\title{
Modelling the partitioning of chlorine between gas and basaltic melts: implications on redox state and degassing behavior of Mt. Etna magmas
}

ROBERTO MORETTI ${ }^{1}$, CHARLES LE LOSQ ${ }^{2}$, DANIEL NEUVILLE ${ }^{2}$ AND SALOMÉ PANNEFIEU ${ }^{2}$

${ }^{1}$ Université de Paris, Institut de Physique du Globe de Paris / Obs. Volcanol. Sismol. Guadeloupe

${ }^{2}$ Université de Paris, Institut de physique du globe de Paris, CNRS

Presenting Author: moretti@ipgp.fr

The solubility mechanism of chlorine in basaltic melts was investigated by using data sets available in the literature. The dissolution of $\mathrm{Cl}$ only as chloride ion in the melt is not sufficient to explain the observed solubility at low concentrations. This evidence is independent of errors associated with mass balance calculations. In fact, we observe no Henrian behavior in the diluted range, which demands a change of $\mathrm{Cl}$ speciation. We thus suggest that chlorine solubility involves i) Cl-bearing metal complexes whose concentration depends on structural conditions, i.e. melt composition, and ii) virtually "free" $\mathrm{Cl}^{-}$anions. For a two-phase (melt+gas) system, water vapor is a stripping agent of chlorine dissolved as chloride. We upgraded the derived expression for Cl-solubility into the $\mathrm{CO}_{2}-\mathrm{H}_{2} \mathrm{O}-\mathrm{H}_{2} \mathrm{~S}_{-} \mathrm{SO}_{2}$-silicate melt model of Moretti and Papale [1] and investigated its performance in reproducing Melt inclusion data from Mt. Etna. We then discuss the comparison with the results in Moretti et al. [2], in which Cl-dissolution was approached by means of ad hoc partition coefficients available in the literature.

[1] R. Moretti and P. Papale, 2004, Chemical Geology 213 (13), $265-280$

[2] R. Moretti et al., 2018, Chemical Geology 482, 1-17 